\title{
Study on the effect of modified zeolite on treating nitrate in water and its influencing factors
}

\author{
Hui Yang ${ }^{1, *}$, Huan $\mathrm{He}^{1}$ and Yujie Yan ${ }^{1}$ \\ ${ }^{1}$ School of Municipal and Environmental Engineering, Shenyang Jianzhu University, Shenyang, Liaoning, China
}

\begin{abstract}
In view of the current application of modified materials in water treatment, the research status of nitrate removal from water by modified zeolite was summarized and analyzed. In this paper, several modification methods of zeolite are summarized, the adsorption mechanism is analyzed, the influencing factors of adsorption are discussed, the adsorption effect of modified zeolite is compared, and the study on the modification of zeolite is prospected.
\end{abstract}

\section{Introduction}

Zeolite is a skeleton structure with pore structure of the mineral, the skeleton structure for silicon oxygen structure and aluminum oxygen tetrahedron, silicon oxygen tetrahedron and aluminum oxygen tetrahedron connected by oxygen atoms, the formation of the pore, so zeolite has a large specific surface area. Zeolite due to its internal more pore can and cation exchange reaction and will not change the basic skeleton of zeolite, so zeolite and cation in the environment for better adsorption and ion exchange, widely used in water treatment ${ }^{[1]}$.

Natural zeolite porosity is not high, so its adsorption efficiency is very general. In order to improve the adsorption efficiency of zeolite, zeolite can be modified. In this paper, several modification methods of zeolite are summarized, the adsorption mechanism and factors affecting the adsorption effect are analyzed, the adsorption effect is compared and some modification methods that may improve the adsorption efficiency are proposed.

\section{Modified materials and characterizat ion methods}

\subsection{Zeolite loading/modified materials and steps}

Zeolite can be modified by organic molecules, for example, $\mathrm{Wu}, \mathrm{D} . \mathrm{L}^{[5]}$ et al. modified $\mathrm{NaY}$ zeolite by using lanthanum and cetyltrimethylammonium bromide. Zeolite can also be loaded with inorganic substances on the surface. For example, $\mathrm{Li}, \mathrm{J}^{[6]}$. et al. used $\mathrm{Fe} 0$-zeolite to treat nitrate pollution in water and make it attached to the surface of zeolite. The properties of loading materials were used to increase the adsorption capacity of modified zeolite on nitrate. Zeolite can also be modified by physical or chemical methods such as the use of ultrasonic wave, adding concentrated sulfuric acid, so that the internal structure of zeolite changes, thereby increasing the porosity of zeolite, to increase the amount of adsorption of zeolite. In recent years, with the deepening of the concept of low environmental load, sustainable development and circular economy, on the premise of guaranteeing the excellent performance of materials, the importance of its environmental friendliness and the realization of high value utilization of natural resources has become the research topic in the field of materials. Zeolite surface load, therefore, carbon as adsorbent to become a hot spot, researchers mostly using natural organic compounds as carbon sources, such as Teimouri ${ }^{[3]}$ and so on use of $\mathrm{Y}$ type zeolite, chitosan and $\mathrm{ZrO} 2 \mathrm{CTS} / \mathrm{ZY} / \mathrm{NanoZrO} 2$ nanocomposite for raw materials preparation. The specific load or modified materials and modification steps are shown in table 1.

Table 1. Zeolite loading/modified materials and modification

\begin{tabular}{|c|c|}
\hline $\begin{array}{l}\text { Loading/modified } \\
\text { materials }\end{array}$ & Modified steps \\
\hline Load HDTMA & $\begin{array}{l}\text { Determination of CEC (ion } \\
\text { exchange capacity) of zeolite. } \\
\text { The amount of Hexadecyl } \\
\text { Trimethyl Ammonium Bromide } \\
\text { (HDTMA) was modified into } \\
\text { adsorbent by } 150 \% \text { of the CEC } \\
\text { content of zeolite. First, } \\
\text { hexadecyl trimethylammonium } \\
\text { bromide was dissolved in a } \\
\text { certain amount of water, then } \\
\text { zeolite was added in proportion } \\
\text { and stirred for } 6 \text { h at } 30^{\circ} \mathrm{C} \text {. After } \\
\text { centrifugation, it was washed } 3 \\
\text { times, dried at } 50 \text { }{ }^{\circ} \mathrm{C} \text {, ground } \\
\text { through a } 40 \text {-mesh sieve, and } \\
\text { sealed in bags for later use. }\end{array}$ \\
\hline
\end{tabular}

*Corresponding author: sz_txin@stu.sjzu.edu.cn 


\begin{tabular}{|c|c|}
\hline $\begin{array}{l}\text { Concentrated } \\
\text { sulfuric acid } \\
\text { modification }\end{array}$ & $\begin{array}{l}\text { Zeolite modified with } 3 \% \\
\text { concentration of concentrated } \\
\text { sulfuric acid, modification time } \\
\text { of } 120 \text { min, modification } \\
\text { temperature of } 60{ }^{\circ} \mathrm{C} \text {, with a } \\
\text { thermostatic oscillator vibration, } \\
\text { modification, after filtering out } \\
\text { zeolite, with deionized water } \\
\text { cleaning zeolite } 2-3 \text { times to } \\
\text { neutral, drying standby. }\end{array}$ \\
\hline $\begin{array}{l}\text { Supported } \\
\text { chitosan }\end{array}$ & $\begin{array}{l}\text { Weighed a certain amount of } \\
\text { zeolite, washed it with deionized } \\
\text { water for several times, and put it } \\
\text { in a } 105{ }^{\circ} \mathrm{C} \text { drying oven for } 2 \\
\text { hours before taking it out and } \\
\text { putting it into a dryer for later } \\
\text { use. } 5 \mathrm{~g} / \mathrm{L} \text { chitosan was dissolved } \\
\text { in } 2 \% \text { acetic acid solution and } \\
\text { prepared into chitosan acetic acid } \\
\text { sol.40 g of dried zeolite } \\
\text { molecular sieve was added to the } \\
\text { chitosan acetic acid sol, and then } \\
\text { put into a thermostatic oscillator, } \\
\text { oscillated at } 130 \mathrm{r} / \mathrm{min} \text { at room } \\
\text { temperature for } 12 \mathrm{~h} \text {, and then } \\
\text { taken out and dried in a vacuum } \\
\text { drying oven }\left(60^{\circ} \mathrm{C}\right) \text { for } 12 \mathrm{~h} \text {, to } \\
\text { prepare chitosan-modified zeolite } \\
\text { composite particles. }\end{array}$ \\
\hline $\begin{array}{l}\text { Microwave } \\
\text { modification }\end{array}$ & $\begin{array}{l}\text { Weigh } 1 \mathrm{~g} \text { of } 100 \text {-mesh zeolite } \\
\text { and add it into } 10 \mathrm{~mL} \text { of distilled } \\
\text { water, microwave it for } 10 \mathrm{~min} \text { at } \\
700 \mathrm{~W} \text { power, and dry it at } \\
105^{\circ} \mathrm{C} \text { for later use. }\end{array}$ \\
\hline $\begin{array}{l}\text { Ultrasonic } \\
\text { modification }\end{array}$ & $\begin{array}{l}1 \mathrm{~g} \text { of } 100 \text { mesh zeolite was } \\
\text { weighed and added into } 10 \mathrm{~mL} \text { of } \\
\text { distilled water. The zeolite was } \\
\text { treated for } 20 \mathrm{~s} \text { under } 100,200 \text {, } \\
300 \text { and } 400 \mathrm{~W} \text { ultrasonic power, } \\
\text { respectively, and dried at } 105^{\circ} \mathrm{C} \\
\text { for later use }\end{array}$ \\
\hline
\end{tabular}

\subsection{Characterization method}

In order to analyze the modification effect of zeolite more accurately, some electronic equipment was used in the experiment to characterize the modified zeolite. Li, X.J. ${ }^{[2]}$ Et al. used HDTMA to modify zeolite, and used Fourier transform infrared spectroscopy (FTIR) to characterize the modified zeolite, through the infrared spectrum analysis can be inferred that HDTMA successfully loaded onto the zeolite. Teimouri ${ }^{[3]}$ Scanning electron microscopy (SEM) was used to analyze the surface and cross section of the adsorbent prepared by $\mathrm{CTS} / \mathrm{ZY} / \mathrm{Nano} \mathrm{ZrO}_{2}$ nanocomposite. The size and shape of the adsorbent were observed. The surface characteristics of the modified zeolite before and after adsorption could be clearly observed by scanning electron microscopy. In addition, the modified zeolite can be characterized by BET surface area analysis (BET), $\mathrm{X}$-ray diffraction (XRD) analysis of the internal crystal structure of the adsorbent, energy dispersive spectroscopy (EDS) analysis of the content of each element, etc.

\section{Adsorption mechanism and influenc ing factors of nitrate adsorption by $\mathrm{m}$ odified zeolite}

\subsection{Study on adsorption mechanism}

\subsubsection{Adsorption kinetics.}

There are two kinds of adsorption kinetics models commonly used in water treatment, which are the quasi-first-order kinetics model and the quasi-second-order kinetics model respectively. Through the analysis and study of adsorption kinetics, the adsorption rate of adsorption kinetics can be estimated, and the reaction mechanism can be deduced, and then the appropriate adsorption kinetics model can be established. The adsorption equilibrium time of nitrate can be obtained by measuring the adsorption amount of nitrate by adsorbent under different adsorption time conditions, and then the adsorption kinetic curve can be obtained. Test dynamic model which are frequently used in the accurate first order kinetics model and quasi secondary dynamics model, the accurate first order kinetics model is put forward by Lagergren, is to assume that the adsorption reaction is affected by diffusion (physical adsorption), the adsorption rate of reaction and adsorption equilibrium adsorption capacity and adsorption in $\mathrm{t}$ time is proportional to the amount of liquid is used to indicate a solid phase adsorption process. The quasi-second-order kinetic model, developed by Ho and McKay, assumes that the adsorption rate is controlled by chemisorption and involves electron transfer or electron sharing between the adsorbate and the adsorbent. During the test, the modified zeolite was added into the nitrate solution, the $\mathrm{pH}$ value of the system was adjusted, and the zeolite was oscillated in a constant temperature shaking table. The sample was taken every once in a while. After standing, the mass concentration of nitrate in the filtrate was determined by filtration membrane. The quasi-first-order and quasi-second-order dynamics models were used to fit the test data. Teimouri ${ }^{[3]}$ Zeolite $\mathrm{Y}$, chitosan and $\mathrm{ZrO}_{2}$ were used $\mathrm{CTS} / \mathrm{ZY} / \mathrm{Nano} \mathrm{ZrO}_{2}$ was prepared for raw materials, Nanocomposite was obtained that the adsorption process of nitrate was in line with the second-order kinetic model, indicating that the adsorption was mainly chemisorption, because the active functional groups such as amino group and hydroxyl group in the molecular structure of the loaded chitosan were connected with the nitrate in the water by chemical bond during adsorption. Wu, D.L $\mathrm{L}^{[5]} \mathrm{Et}$ al. modified NaY zeolite with lanthanum and cetyltrimethylammonium bromide, and the adsorption process was in line with the second-order kinetic model. This shows that zeolite modified with chemical adsorption is given priority to, more additional zeolite 
itself to cation adsorption, adsorption of anionic ability is poorer, modified adsorption ability stronger illustrates the main adsorption materials mainly load up (form chemical bonds), it also confirms the adsorption process conforms to the level 2 dynamic model is the result of chemical adsorption.

\subsubsection{Study on adsorption isotherm.}

Adsorption isotherm refers to the relationship between the adsorption equilibrium concentration of adsorbents in solution and the adsorption amount of adsorbents under certain temperature conditions. Langmuir adsorption isotherm model and Freundlich adsorption isotherm model are relatively common adsorption isotherm models. The experimental data obtained in the adsorption test were fitted through Langmuir adsorption isotherm model and Freundlich adsorption isotherm model respectively, and then the appropriate adsorption isotherm model was obtained. The Langmuir adsorption isotherm model assumes that the surface of the adsorbent is uniform and the adsorption is monolayer, and there is no interaction between the adsorbed molecules. The Freundlich adsorption isotherm model assumes that the adsorption sites increase exponentially with the increase of temperature. It is used to describe that the surface of the adsorbent is not uniform and the adsorption is multi-layer at the same time. During the operation, the modified zeolite will be weighed, and nitrate solutions with different mass concentration gradients will be added to adjust the solution to the optimal $\mathrm{pH}$ value for adsorption. The mixed solution will oscillate in the thermostat. After the oscillation, the mass solubility of nitrate in the filtrate will be measured by filtration membrane. The nitrate adsorption capacity per unit mass of adsorbent was calculated and plotted. The data were fitted by Langmuir and Freundlich models respectively. $\mathrm{Wu}$, D.L ${ }^{[5]} \mathrm{Et}$ al. modified $\mathrm{NaY}$ zeolite with lanthanum and cetyltrimethylammonium bromide, and the adsorption equilibrium process of modified zeolite for nitrate was more consistent with Langmuir model (R2Is 0.9988), the same as this conclusion Teimouri ${ }^{[3]}$ The adsorption equilibrium process of CTS/ Zy $/ \mathrm{Nano} \mathrm{ZrO}_{2}$ nanocomposite prepared by et al also fits Langmuir model, indicating that the adsorption of nitrate by modified zeolite is mostly monolayer adsorption.

\subsection{Study on adsorption influencing factors}

In order to study the influencing factors of adsorption, a static adsorption test is needed. The static adsorption test includes the influence of adsorbent dosage, adsorption time, adsorption temperature and adsorption $\mathrm{pH}$ value on the adsorption effect. Cheng, $T{ }^{[4]}$ Zeolite modified by concentrated sulfuric acid was used to adsorb and remove nitrate in water. The optimal adsorption conditions were as follows: adsorbent dosage of $1 \mathrm{~g}$, adsorption time of $2 \mathrm{~h}$, adsorption temperature of $55{ }^{\circ} \mathrm{C}$ and $\mathrm{pH}$ value of 6 . Teimouri ${ }^{[3]}$ Zeolite $\mathrm{Y}$, chitosan and $\mathrm{ZrO}_{2}$ were used $\mathrm{CTS} / \mathrm{ZY} / \mathrm{Nano} \mathrm{ZrO}_{2}$ was prepared for raw materials. The optimum adsorption conditions of nanocomposite were as follows: dosage of $0.02 \mathrm{~g}$, adsorption time $1 \mathrm{~h}$, adsorption temperature $35^{\circ} \mathrm{C}, \mathrm{pH} 3$. Comparing the best adsorption conditions of several modified zeolite, it is found that the adsorption dosage, adsorption time and adsorption temperature are greatly different, although the $\mathrm{pH}$ value is acidic but the specific value is still different, so the best adsorption conditions for each modified zeolite need to be obtained through specific tests and there is no unified range.

\section{Study on the adsorption effect of modified zeolite on nitrate}

The adsorption effect of modified zeolite is the key to evaluate the quality of adsorbents. $\mathrm{Li}, \mathrm{J}{ }^{[6]} \mathrm{The}$ results show that when the concentration of nitrate in water is 40 $\mathrm{mg} / \mathrm{L}$, the removal rate of nitrate is about $63 \%$. Teimouri ${ }^{[3]}$ The adsorption effect of CTS/ZY/Nano $\mathrm{ZrO}_{2}$ nanocomposite prepared by et al on nitrate is as follows: when the nitrate concentration is $20 \mathrm{mg} / \mathrm{L}$, the removal rate can reach $40.28 \%$. Yu, H.Y. ${ }^{[14]}$ et al. modified zeolite by microwave, and the nitrate adsorption rate of zeolite increased from $83 \%$ to $90 \%$ before and after microwave modification. They also modified zeolite by ultrasonic wave, and the nitrate adsorption rate of the modified zeolite was also improved.

Because the initial concentration of nitrate in the test of each modified zeolite is different, the excellent adsorption effect of each modified zeolite is difficult to be directly compared. Therefore, if you want to compare the adsorption effect of two kinds of adsorbents, you need to give the initial concentration of nitrate first, and then compare.

At present about experimental study of modified zeolite to remove nitrate in water is less, the modification methods of zeolite has been greatly the research of space, for example, you can try to load again after zeolite acid to increase the porosity chitosan methods to further increase the adsorption quantity, or try to load by certain proportion of two different materials, or try again other materials on the market for the load. Nowadays, scientific research workers generally pay attention to the best adsorption capacity of zeolite in the adsorption process. There are still few studies on whether the zeolite material can be physically regenerated or chemically regenerated, and how to improve the removal rate of pollutants by hydrogel.

Zeolite itself is a relatively cheap mineral material, modified zeolite adsorption materials prepared by modification has a good adsorption performance to pollutants, in the field of water treatment has a broad application prospect. However, most of the studies on the preparation and application of such modified zeolite adsorption materials are still in the stage of basic development in the laboratory, and many factors need to be considered in the future to promote and apply them in the actual industrial water treatment process. 


\section{Conclusion}

The modification methods of zeolite can be divided into loading other materials and physical or chemical modification. After modification, zeolite can be characterized by SEM, FTIR, BET and other methods, and the optimal adsorption conditions can be determined by static adsorption test. The adsorption process of nitrate by modified zeolite conforms to the second-order kinetics and Langmuir adsorption isotherm, that is, chemisorption and monolayer adsorption are the main processes. As an adsorbent, modified zeolite has a good adsorption performance to pollutants, and has a broad application prospect in removing nitrate from water. At present, most of the research is in the laboratory test stage, and there is still a long way to popularize it and apply it to the actual water plant.

\section{Acknowledgments}

Thanks to the support of the "13th five-year plan" water research group for this study, the integration and application of water pollution control and water environment management technology in liaohe river basin, the subject of this study (2018ZX07601001), provided the data of this study. I would like to thank the teachers of the school of environment of Shenyang jianzhu university for their hard work and the students who helped me with this paper.

\section{References}

1. Jin, Z.F., Li, W.T., Pan, Z.Y., Chen, Y.X. (2006). J. Water Treatment Technology, 8: 34-37.

2. Li, X.J., Wang, D.H. (2011) Adsorption mechanism of nitrate in water by modified zeolite and utilization of residue. J. Journal of China Environmental Management Cadre Academy, 21: 13-17.

3. Teimouri, A., Nasab, S.G., Vahdatpoor, N., Habibollahi, S., Salavati H., Chermahini, A.N. (2016) Chitosan /Zeolite Y/Nano $\mathrm{ZrO}_{2}$ nanocomposite as an adsorbent for the removal of nitrate from the aqueous solution. J. International journal of biological macromolecules, 93: Pt A.

4. Cheng, T. (2020) Study on the adsorption characteristics of nitrate in water by sulfuric acid modified zeolite . J. Sichuan Chemical Industry, 23: $39-42$.

5. Wu, D.L., Sun, Y., Wang, L.L., Zhang, Z.M., Gui, J.X., Ding, A.Q. (2020) Modification of NaY zeolite by lanthanum and hexadecyl trimethyl ammonium bromide and its removal performance for nitrate. J. Water Environment Research, 92.

6. Li, J., Yao, S.T., Feng, L., Zhang, S.Y., Yang, S. (2011) Experimental study on the removal of nitrate from water by $\mathrm{Fe} \sim 0$ - zeolite. J. Journal of Shenyang Jianzhu University (Natural Science Edition), 27: 564-568.

7. He, S., Wang, H.F., Zhang, Y.X., Ren, Z.Y., Tang,
C.Q. (2014) Removal of nitrate from groundwater by chemical/biological combined PRB technology. J. China Water \& Wastewater, 30: 48-51.

8. Guo, Y., Chen, L.J., Wen, D.H. (2006) Study on nitrite nitrogen accumulation in zeolite biological aerated filter. J. China Water \& Wastewater, 9: 73-77.

9. Gao, Y.N., Zhou, L.T., Ru, Y.F., Wang, J., Sun, M.Q., Fu, J.X. (2019) Removal of nitrate from low temperature water by chitosan modified 4A zeolite particles. J. Research of Environmental Sciences, 32: 523-531.

10. Yang, Y.X., Wang, H., Zhao, H.Z. (2018) Adsorption of nitrate and phosphate on covalent quaternary ammonium activated carbon. J. Acta Scientiarum Naturalium Universitalium, 54: 1046-1052.

11. Chen, T.T., Wang, Z.S. (2008) Journal of Hazardous Materials. 01: 131-132.

12. Zhang, C.L., Hu X.M., Ying S.Y., et al. (2013) Preparation of quaternary ammonium salt magnetic particles of chitosan and its adsorption effect on methyl orange. J. Environmental Science, 34: 1815-1821.

13. Wang, M., Fang, C.S., Yan, C.Z., Wei Q.S., Wang Z.S. (2012) Research of Environmental Sciences, 25: 1024-1029. (in Chinese)

14. Yu, H.Y., Yu, Z.M., Song, X.X., Yuan, Y.Q., Cao, X.H. (2013) Treatment of nitrate and nitrogen isotopes in seawater by zeolite, J, Marine Science, 37: 6-10.

15. Lin, D.F., Yang, J.W., Deng, Y.Y., Dai, M., Zheng, X.L., Peng, C.S. (2020) Preparation of spherical hydrogel adsorption materials by titration-gel method and its application in wastewater treatment, $\mathrm{J}$, Chemical Engineering Journal, 71: 914-922.

16. Zhu, Y.F., Zong, L., Yu, H., Wang, A.Q. (2020) Advances in attapulgite adsorption materials for water treatment, J, Bulletin of the Chinese Ceramic Society, 39: 2308-2320.

17. Wei, Y., Cheng, C., Lu, L., Zhang, J., Yu, J., Xie, Y.H (2012) Study on the adsorption and removal of nitrate from water by crosslinked chitosan quaternary ammonium salt, J, Technology of Water Treatment, 38: 21-25.

18. Gao, Y.N., Zhou, L.T., Wang, J., Sun, M.Q., Fu, J.X. (2018) Environmental Engineering, 36: 108-112+176.

19. Sun, L., Yuan, Z.G., Gong, W.B., Xu, Z.L., Han, D.G. (2015) The mechanism study of trace $\mathrm{Cr}(\mathrm{VI})$ removal from water using Fe 0 nanorods modified with chitosan in porous anodic alumina, J, Applied Surface Science, 328.

20. Guo, Y.G., Zhao, Y., Guo, Y.J., Li, X.G., Peng, X., Li, C.L., Liu, W.F. (2015) Removal of ammonia nitrogen from water by chitosan coated mesoporous microporous molecular sieves, J, Chinese Journal of Environmental Engineering, 9: 2067-2072. 